\title{
Load Flow Computation via Artificial Bee Colony Algorithm
}

\author{
Husham M. Nayyef \\ Electrical Engineering Dep., \\ Faculty of Engineering, \\ Al mustansiriyah University \\ Baghdad,Iraq
}

\author{
K. Al-Anbarri, PhD \\ Electrical Engineering Dep., \\ Faculty of Engineering, \\ Al mustansiriyah University \\ Baghdad,Iraq
}

\begin{abstract}
This paper proposes the application of artificial bee colony $\mathrm{ABC}$ algorithm to the load flow computation in power systems. The proposed algorithm is based on a metaheuristic searching technique and it's used to avoid the ill-conditioning problem of Jacobain matrix. The load flow problem is addressed as an optimization problem. ABC algorithm is considered as a new computational model for the system power flow obtainment, where this model provides a strong convergence. The results obtained reveal the importance of the proposed algorithm in finding a load flow solution of a highly stressed power system and ill- conditioned system as compared with traditional methods such as the NewtonRaphson method, where the Newton-Raphson method diverges due to problems of the Jacobian matrix in these situations. The proposed algorithm is applied for 6-bus and 14-bus systems.
\end{abstract}

\section{Keywords}

Load Flow Studies, Newton-Raphson Method, Artificial Bee Colony Algorithm, highly loaded system, Ill-conditioned system.

\section{INTRODUCTION}

Load flow calculations are very important in power system analysis. It can be considered as a basic in power system planning and operation. Given a particular loading status of the system, the load flow study aims to find the bus voltages (magnitudes and angles) and the power flow in transmission lines. So far, several numerical techniques have been used efficiently to solve load flow problem [1-2]. Unfortunately, these techniques suffer from slow convergence and sometimes divergence when the power system operates in ill-conditioned situations such as the prescribed range of $(\mathrm{R} / \mathrm{X})$ ratio for a transmission line in power system is high or when the system is heavily loaded. Theoretically, for $n$ bus system, there are ( $2^{n-1}$ ) solutions for load flow problem. Some of these solutions are stable and the remaining unstable [3-4]. Dynamically, when the system is heavily loaded, the stable and unstable solutions will be close to each other and eventually they become one solution at particular loading condition, which is referred to as the maximum loadability point. In dynamic literature, this point also called saddle-node bifurcation point [5]. The conventional load flow techniques fail to converge near this point due to small eigenvalues of Jacobain matrix; where the jacobaib matrix tends to be singular (i.e. (det:(J) $\cong 0$ ) [6]. Several methods have been developed to avoid singularity of the traditional load flow jacobian by adopting continuation power flow [7-8]. Recently, the fields of swarm intelligence have attracted many researches as a branch of artificial intelligence that deals with the collective behaviour of swarms such as flocks of bird, colonies of aunts, schools of fish, swarm of bees [9-10]. The important features of swarm intelligence are self-organization, scalability, adaptation, speed. The swarm intelligence techniques have been applied in many power system studies [11-14] .In this paper, the load flow problem is approached as an optimization problem by using swarm intelligence. The objective function is to minimize the power mismatch. This paper is organized as follows: section 2 reviews the NewtonRaphson (NR) technique in solving load flow problem. The basics model of $A B C$ is presented in section 3. Section 4 discusses the results obtained by applying the proposed algorithms on a typical system. Finally, section 5 presents the conclusion.

\section{FORMALTION OF LOAD FLOW EQUATIONS}

The electrical power system consists of various buses; these buses are interconnected through transmission lines. Each line has series impedance $(Z)$ in addition to the total line charging admittance (y). The unknown variables in load flow study are the voltage magnitude and phase angle of the bus voltage in power system.

The net current injected at bus $i$ into $\mathrm{N}$ bus system is given by the following Equation:

$I_{i}=Y_{i 1} V_{1}+Y_{i 2} V_{2}+\cdots+Y_{i N} V_{N}=\sum_{n=1}^{N} Y_{i n} V_{n}$

Where:

$Y_{\text {in }}=Y_{\text {in }} \angle \theta_{\text {in }}=$ The element of admittance matrix $\left(Y_{\text {bus }}\right)$. $V_{n}=V_{n} \angle \delta_{n}=$ The voltage magnitude $\left|V_{n}\right|$ of bus $\mathrm{n}$ and $\delta_{n}$ is the voltage angle of $n$.

The apparent power entering into the system at bus $i$ is:

$S_{i}^{*}=V_{i}^{*} I_{i}=V_{i}^{*} \sum_{i n}^{N} Y_{\text {in }} V_{n}$

The net active and reactive power injected into the system at bus $i$ is:

$P_{i}-j Q_{i}=V_{i}^{*} \sum_{i n}^{N} Y_{i n} V_{n}$

By substituting Equation (1) into (3), we obtain: 
$P_{i}-j Q_{i}=\sum_{n=1}^{N}\left|Y_{i n} V_{i} V_{n}\right| \angle\left(\theta_{i n}+\delta_{n}-\delta_{i}\right)$

Resolving the equation above into the real and imaginary parts

$P_{i}=\sum_{n=1}^{N}\left|Y_{i n} V_{i} V_{n}\right| \cos \left(\theta_{\text {in }}+\delta_{n}-\delta_{i}\right)$

$Q_{i}=-\sum_{n=1}^{N}\left|Y_{i n} V_{i} V_{n}\right| \sin \left(\theta_{\text {in }}+\delta_{n}-\delta_{i}\right)$

Where:

$P_{i}$ and $Q_{i}$ represent the net active and reactive power respectively.

The net scheduled power at bus $i$ is:

$P_{i . s c h}=P_{g i}-P_{d i}$

Where:

$\mathrm{P}_{\mathrm{gi}}=$ The scheduled power that generated at bus $(i)$.

$\mathrm{P}_{\mathrm{di}}=$ The scheduled power demand of load at bus (i).

So, the mismatch of active power $\left(\Delta P_{i}\right)$ at bus $i$ is:

$\Delta P_{i}=P_{i . s c h}-P_{i . c a l}=\left(P_{g i}-P_{d i}\right)-P_{i . c a l}$

Similarly, the mismatch of reactive power $\left(\Delta Q_{i}\right)$ at bus $i$ is:

$\Delta Q_{i}=Q_{i . s c h}-Q_{i . c a l}=\left(Q_{g i}-P_{d i}\right)-P_{i . c a l}$

where $P_{i . c a l}$ and $Q_{i . c a l}$ are calculated from equations (5) \& (6) at guess values.

Equations (5) \& (6) represent a non-linear power flow equations; these equations can be solved numerically by NR method [15]. By applying Taylor series expansion to equations (5) \& (6), the linearized form of these equations can be expressed as:

$\left[\begin{array}{l}\Delta P \\ \Delta Q\end{array}\right]=\left[\begin{array}{ll}J_{1} & J_{2} \\ J_{3} & J_{4}\end{array}\right]\left[\begin{array}{l}\Delta \delta \\ \Delta V\end{array}\right]$

Where $J_{1}, J_{2}, J_{3}$ and $J_{4}$ are the elements of jacobian matrix, which represented the partial derivatives of $P_{i}$ and $Q_{i}$ with respect to corresponding $\delta$ and $|V|, \Delta \delta$ and $\Delta V$ are the correction values.

The correction values in the $\mathrm{k}^{\text {th }}$ iteration as follows:

$\delta_{i}^{(k+1)}=\delta_{i}^{(k)}+\Delta \delta_{i}^{(k)}$

$V_{i}^{(k+1)}=V_{i}^{(k)}+\Delta V_{i}^{(k)}$

The main steps of NR method implementation [15]:

1. Assume the initial guess values for state variables $\boldsymbol{\delta}_{\boldsymbol{i}}^{(\mathbf{0})}$ and $\left|\boldsymbol{V}_{\boldsymbol{i}}\right|^{(\mathbf{0})}$

2. Use the initial values to compute $P_{i . c a l}^{(0)}$ and $Q_{i . c a l}^{(0)}$ from Eqs. (5) and (6), in addition to the partial derivative elements of Jacobian matrix.

3. Now, solve the equation (10) by using the initial corrections values $\left(\Delta \delta_{i}^{(0)}\right.$ and $\left.\left|V_{i}\right|^{(0)} /\left|V_{i}\right|^{(0)}\right)$.

4. Add the corrections that obtained previously to the initial values of state variables $\delta_{i}^{(0)}$ and $\left|V_{i}\right|^{(0)}$ to obtain:

$$
\begin{gathered}
\delta_{i}^{(1)}=\delta_{i}^{(0)}+\Delta \delta_{i}^{(0)} \\
V_{i}^{(1)}=V_{i}^{(0)}+\Delta V_{i}^{(0)}
\end{gathered}
$$

5. Use the new values of state variables $\delta_{i}^{(1)}$ and $\left|V_{i}\right|^{(1)}$ as initial value to the second iteration and continues. This process continues until the power mismatches $\Delta P_{i}$ and $\Delta Q_{i}$ satisfy convergence conditions and the convergence conditions is

$\left\|\Delta P^{k}, \Delta Q^{k}\right\|<\varepsilon$

Where $\varepsilon=$ the tolerance which usually set between $\left(10^{-4}\right.$ $\left.10^{-6}\right)$; and $\left\|\Delta P^{k}, \Delta Q^{k}\right\|$ is a norm, which represented the maximum element in power mismatches vector $(\Delta P$ and $\Delta Q)$.

\section{ARTIFICIAL BEE COLONY ALGORITHM APPLIED TO THE LOAD FLOW COMPUTATION}

\subsection{Artificial bee colony algorithm}

$\mathrm{ABC}$ algorithm is one of the newest optimization algorithms that mainly based on the collective behaviour of insects colonies and other animal societies. The $\mathrm{ABC}$ algorithm is inspired by the nature behavior of honey bee swarm in search of food sources. This algorithm uses a certain communication way to find the best food sources. The purpose of use ABC algorithm is to solve multidimensional and multimodal optimization problems. Karaboga proposed the ABC algorithm in 2005[9]; he applied this behavior of honey bee swarm in his work to solve numerical problems. In this algorithm, the bee colony consists of three groups: employed bees, onlookers and scouts. The bee colony is divided into two halves, the first half of colony includes employed bees; and the second half includes the onlookers. These bees will search the food sources by using certain behaviors among them. The scouts bees begin to search for food sources randomly, when the scouts find the food sources, they convert to employed bees, then return to the hive and execute the waggle dance to exchange the information about the quality and position of the food sources with onlooker bees. Then, the onlooker bees will select the best food source position based on the waggle dance information. After finding the food source, the abandoned food sources are determined and replaced with new randomly generated ones by the scout bees. Each time the employed and onlooker bees finish their job, the optimal food source are registered. To utilize the $\mathrm{ABC}$ algorithm, there is some control parameters that should be set [16]; They are number of variables (Nvar), lower bound of variables (Lb), upper bound of variables (Ub), population size (colony size) (nPop), number of onlooker bees (nOnlooker), maximum number of iterations (MaxIt)(the stopping criteria), abandonment limit parameter (Limit) and acceleration coefficient upper bound (A).

\subsection{Steps of $\mathrm{ABC}$ implementation [17]}

1. Initialize the solutions (food sources)

2. Evaluate the population (the nectar quantity)

3. Generate new solutions (food sources) by using neighborhood search

4. Apply the roulette wheel selection (choose the best fit individuals).

5. Calculate the probability rate $(\mathrm{Pi})$ related with solutions; 


$$
P_{i}=\frac{f i t_{i}}{\sum_{i=1}^{S N} f i t_{i}}
$$

The fitness values (fit) computed which expressed as:

$$
\text { fit }_{i}= \begin{cases}\frac{1}{1+f_{i}} & \text { if } f_{i} \geq 0 \\ 1+a b s\left(f_{i}\right) & \text { if } f_{i}<0\end{cases}
$$

Usually, the value of $\mathrm{Pi}$ is between $\{0,1\}$.

6. Find the new solutions for the onlookers depending on the probability Pi related with the solutions.

7. Re-apply roulette wheel selection.

8. Find the abandoned solution if exists, change it with new randomly generated solution.

9. Register the best solution achieved so far.

10. Cycle $=$ cycle +1 (until maximum cycle number is reached).

\subsection{ABC application for load flow computation}

ABC optimization is applied to obtain the bus voltage magnitude $\left(\left|V_{i}\right|\right)$ and voltage phase angle $\left(\delta_{i}\right)$ by minimize the value of objective function [18], which gives as:

$$
\min f(x), x=\left(x_{1}, x_{2}, \ldots, x_{i}, \ldots, x_{n-1}, x_{n}\right)
$$

This objective function constrained by the inequalities lower bound $(\mathrm{Lb})$ and upper bound $(\mathrm{Ub})$.

$L b \leq x_{i} \leq U b$

The optimization process starts with setting the number of solutions (food sources) in (ABC) algorithm, which represent the number of flowers, the bees will reach to food sources, and then compute the nectar's quantity, the food sources are initialized by using a random number generator.

The voltage magnitude and voltage phase angle are limited in range $0.5 \leq V_{i} \leq 1.05$ and $-5 \leq \delta_{i} \leq 5$

The objective function $(\mathrm{F})$ that designed to determine the load flow problem by using $\mathrm{ABC}$ algorithm is:

$\mathrm{F}=\sqrt{\sum \Delta P i^{2}+\sum \Delta Q i^{2}}$

where $i=1,2,3 \ldots$ number of bus bars

In $\mathrm{ABC}$ algorithm, the objective function (fitness value) describes the quality of food source (solution). The food source that has the best quality will be registered in a memory as a best food source (solution) ever found. The neighborhood search process that uses to obtain the best fitness value will continue by employed bees and onlookers. The fitness value will be computed for each new solution (food source), the new solution (food source) that having the best fitness value will be the new reference in memory. The optimization process will continue to looking for the food source near to hive, which depending on the probability that computed previously from fitness value. The new solution (food source) after neighborhood search will be registered if its fitness value is better. The optimization process will continue until reach to the best fitness value or reach to the maximum cycle number afterwards the solution converges and the mismatch power is close to zero the whole application of $\mathrm{ABC}$ algorthim approach in load flow computation is as shown in Fig(1).

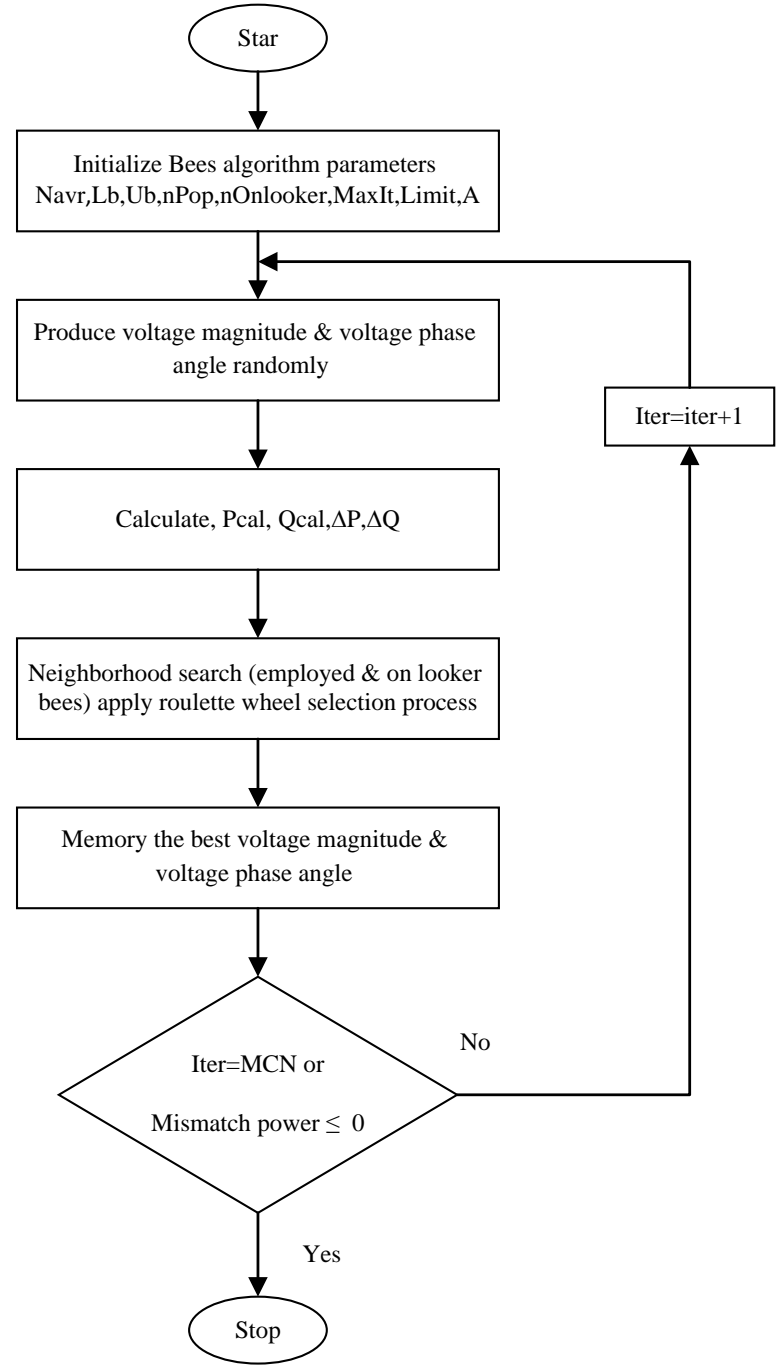

Figure 1: Application ABC algorithm in load flow solution

\section{RESULTS AND DISCUSSION}

The $\mathrm{ABC}$ algorithm is being applied to the 6 and 14 IEEE bus system as follows:

\subsection{Test case 6 - bus system}

The ABC method is applied to the 6-bus system with a particular loading condition [19] shown in Figure (2). After initialize the control parameters of $\mathrm{ABC}$ algorithm, each variable was initialized with random number using random number generator. The elements of power mismatches vector $(\Delta \mathrm{P}$ and $\Delta \mathrm{Q})$ are computed using Esq. (8) \& (9). The best food source (load flow solution) will be selected by applying roulette wheel selection.

A comparison between the results that obtained from conventional NR methd with that found from $\mathrm{ABC}$ algorithm are given in table (1), (2) and (3). As shown from these tables, the results obtained are roughly identical. The final objective function value in $\mathrm{ABC}$ optimization process after 15000 iteration is $1.5902 \times 10^{-11}$. The performance of $\mathrm{ABC}$ algorthim to obtain the best solution is clarified by graph that shown in Figure (3). 


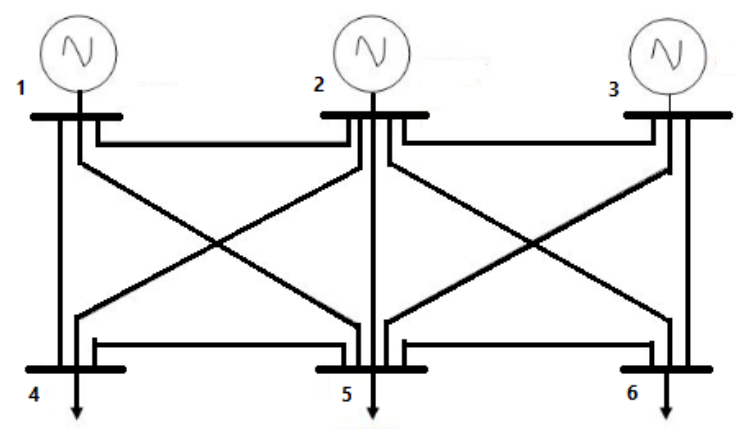

Figure 2: Test case 6-bus system

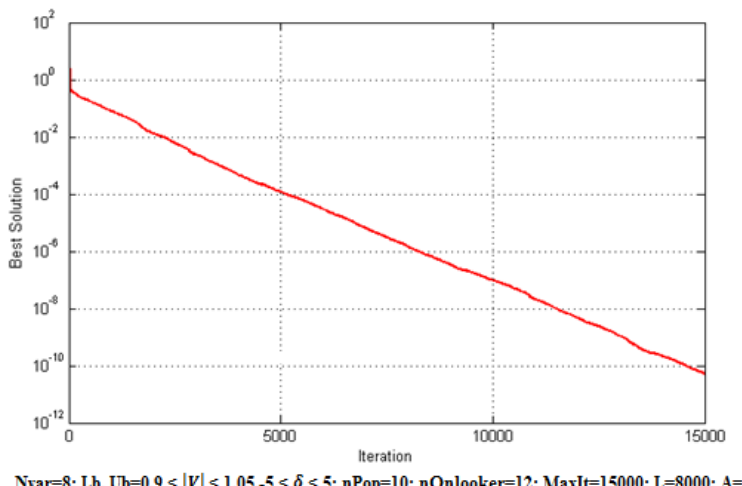

Figure 3: The performance of $\mathrm{ABC}$ algorithm, best solution versus iteration

Table 1: Results of system (bus voltages)

\begin{tabular}{|c|c|c|c|c|}
\hline \multirow{2}{*}{$\begin{array}{c}\text { Bus No. } \\
\text { (i) }\end{array}$} & \multicolumn{2}{|c|}{ NR-method } & \multicolumn{2}{c|}{ ABC-algorithm } \\
\cline { 2 - 5 } & $\mathrm{V}_{\mathrm{i}}$ & $\delta_{\mathrm{i}}$ & $\mathrm{V}_{\mathrm{i}}$ & $\delta_{\mathrm{i}}$ \\
\hline 1 & 1.05 & 0.0 & 1.05 & 0.0 \\
\hline 2 & 1.05 & -3.63504 & 1.05 & -3.635016 \\
\hline 3 & 1.07 & -4.11771 & 1.07 & -4.117675 \\
\hline 4 & 0.98901 & -4.18073 & 0.989013 & -4.180701 \\
\hline 5 & 0.98316 & -5.30650 & 0.981364 & -5.306448 \\
\hline 6 & 1.00408 & -5.85697 & 1.004079 & -5.856946 \\
\hline
\end{tabular}

Table 2: Results of system by using NR method (power flow in lines)

\begin{tabular}{|c|c|c|c|c|c|}
\hline \multicolumn{2}{|c|}{ The lines } & \multirow{2}{*}{$\begin{array}{c}\mathrm{P}_{\mathrm{ij}} \\
(\mathrm{MW})\end{array}$} & \multirow{2}{*}{$\begin{array}{c}\mathrm{Q}_{\mathrm{ij}} \\
\text { (MVAR) }\end{array}$} & \multirow{2}{*}{$\begin{array}{c}\mathrm{P}_{\mathrm{ji}} \\
(\mathrm{MW})\end{array}$} & \multirow{2}{*}{$\begin{array}{c}\mathrm{Q}_{\mathrm{ji}} \\
(\mathrm{MVAR})\end{array}$} \\
\hline $\mathrm{i}$ & $j$ & & & & \\
\hline 1 & 2 & 28.4034 & -13.0927 & -27.5162 & 14.8671 \\
\hline 1 & 4 & 43.4856 & 22.5284 & -42.3978 & -18.1773 \\
\hline 1 & 5 & 35.9025 & 15.2932 & -34.7974 & -11.1493 \\
\hline 2 & 3 & 2.0279 & -8.7896 & -1.9910 & 8.9741 \\
\hline 2 & 4 & 33.5456 & 47.3105 & -32.0202 & -44.2596 \\
\hline 2 & 5 & 16.0950 & 18.1738 & -15.5604 & -16.5702 \\
\hline 2 & 6 & 25.8477 & 15.4578 & -25.2718 & -13.8123 \\
\hline 3 & 5 & 16.9774 & 24.2558 & -16.0586 & -21.9589 \\
\hline 3 & 6 & 45.0136 & 62.0269 & -43.9875 & -56.8967 \\
\hline 4 & 5 & 4.4180 & -0.7160 & -4.3770 & 0.7979 \\
\hline
\end{tabular}

Table 3: Results of system by using (ABC) algorithm (power flow in lines)

\begin{tabular}{|c|c|c|c|c|c|}
\hline \multicolumn{2}{|c|}{ The lines } & \multirow{2}{*}{$\begin{array}{c}\mathrm{P}_{\mathrm{ij}} \\
\text { (MW) }\end{array}$} & $\begin{array}{c}\mathrm{Q}_{\mathrm{ij}} \\
\text { (MVAR) }\end{array}$ & $\begin{array}{c}\mathrm{P}_{\mathrm{ji}} \\
(\mathrm{MW})\end{array}$ & $\begin{array}{c}\mathrm{Q}_{\mathrm{ji}} \\
(\mathrm{MVAR})\end{array}$ \\
\cline { 1 - 2 } 1 & $\mathrm{j}$ & 28.4032 & -13.0926 & -27.5160 & 14.8670 \\
\hline 1 & 4 & 43.4853 & 22.5285 & -42.3975 & -18.1775 \\
\hline 1 & 5 & 35.9022 & 15.2934 & -34.7972 & -11.1496 \\
\hline 2 & 3 & 2.0278 & -8.7896 & -1.9909 & 8.9741 \\
\hline 2 & 4 & 33.5455 & 47.3107 & -32.0201 & -44.2598 \\
\hline 2 & 5 & 16.0949 & 18.1740 & -15.5603 & -16.5704 \\
\hline 2 & 6 & 25.8480 & 15.4581 & -25.2720 & -13.8126 \\
\hline 3 & 5 & 16.9774 & 24.2560 & -16.0586 & -21.9591 \\
\hline 3 & 6 & 45.0143 & 62.0276 & -43.9883 & -56.8973 \\
\hline 4 & 5 & 4.4180 & -0.7159 & -4.3770 & 0.7978 \\
\hline
\end{tabular}

\subsection{Test case 6-bus system with a heavy load condition}

To simulate the heavy load condition the load at bus 4, 5 and 6 are increased as shown in appendix A. It is found that the conventional NR method is failed to converge. However, when the $\mathrm{ABC}$ algorithm is applied, the solution converges as shown in tables (4) \& (5). The final objective function value in $\mathrm{ABC}$ optimization process after 5000 iteration is $8.99 \times$ $10^{-4}$. The performance of $\mathrm{ABC}$ method to obtain the best solution is clarified by graph that shown in Figure (4).

Table 4: Results of system by using ABC algorithm (buses voltages)

\begin{tabular}{|c|c|c|}
\hline $\begin{array}{c}\text { Bus No. } \\
\text { (i) }\end{array}$ & $V_{i}$ & $\delta_{\mathrm{i}}$ \\
\hline 1 & 1.0500 & 0 \\
\hline 2 & 1.0500 & -52.3630 \\
\hline 3 & 1.0700 & -63.0819 \\
\hline 4 & 0.7575 & -46.0854 \\
\hline 5 & 0.6721 & -58.3285 \\
\hline 6 & 0.8341 & -68.0498 \\
\hline
\end{tabular}

Table 5: Results of system by using $\mathrm{ABC}$ algorithm (power flow in lines)

\begin{tabular}{|c|c|c|c|c|c|}
\hline \multicolumn{2}{|c|}{ The lines } & \multirow{2}{*}{$\begin{array}{c}\mathrm{P}_{\mathrm{ij}} \\
(\mathrm{MW})\end{array}$} & \multirow{2}{*}{$\begin{array}{c}\mathrm{Q}_{\mathrm{ij}} \\
(\mathrm{MVAR})\end{array}$} & \multirow{2}{*}{$\begin{array}{c}\mathrm{P}_{\mathrm{ji}} \\
(\mathrm{MW})\end{array}$} & \multirow{2}{*}{$\begin{array}{c}\mathrm{Q}_{\mathrm{ji}} \\
(\mathrm{MVAR})\end{array}$} \\
\hline $\mathrm{i}$ & $\mathrm{j}$ & & & & \\
\hline 1 & 2 & 435.0761 & -2.9125 & -263.375 & 346.3134 \\
\hline 1 & 4 & 334.4332 & 191.8157 & -267.023 & 77.8239 \\
\hline 1 & 5 & 247.6581 & 177.9457 & -180.175 & 75.1133 \\
\hline 2 & 3 & 80.2621 & -16.611 & -77.2154 & 31.8444 \\
\hline 2 & 4 & 55.1868 & 284.3133 & -17.1462 & -208.232 \\
\hline 2 & 5 & 62.0638 & 112.8464 & -47.0196 & -67.7138 \\
\hline 2 & 6 & 145.9062 & 78.5922 & -128.467 & -28.7684 \\
\hline 3 & 5 & 43.7692 & 144.496 & -19.8774 & -92.7303 \\
\hline 3 & 6 & 123.5007 & 231.0694 & -111.509 & -171.111 \\
\hline 4 & 5 & 29.2177 & 4.4536 & -26.1730 & 1.6358 \\
\hline
\end{tabular}




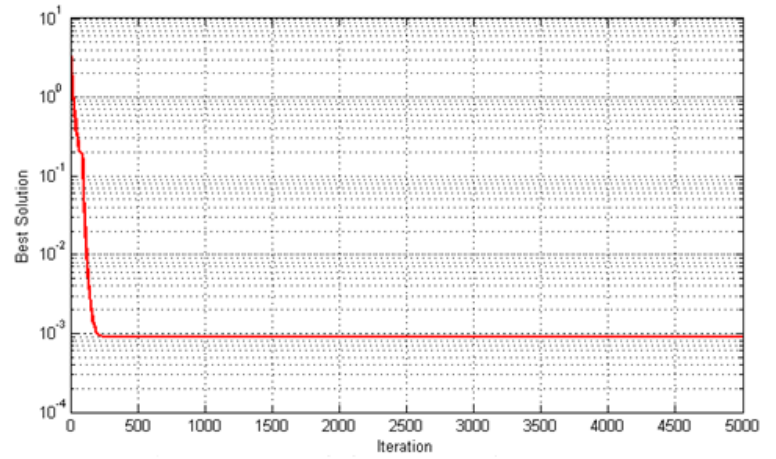

Nvar=8; Lb, Ub=0.5 $\leq|V| \leq 1.05,-5 \leq \delta \leq 5 ; \mathrm{nPop}=6$; nOnlooker=8; Maxit=500; $\mathrm{L}=300 ; \mathrm{A}=1$.

Figure 4: the performance of $\mathrm{ABC}$ algorithm, best solution versus iteration

\subsection{Test case 14-bus system}

The ABC method is applied to the 14-bus system with a particular loading condition (bus data given in appendix B.) Shown in Fig (8) [20]. After initialize the control parameters of $\mathrm{ABC}$, the $\mathrm{ABC}$ algorithm give similar results in comparison with the conventional NR method as shown in table (6), (7) and (8). The final objective function value in $\mathrm{ABC}$ optimization process after 200000 iteration is $1.9147 \times$ $10^{-8}$. The performance of $\mathrm{ABC}$ method to obtain the best solution is clarified by graph that shown in Figure (6).

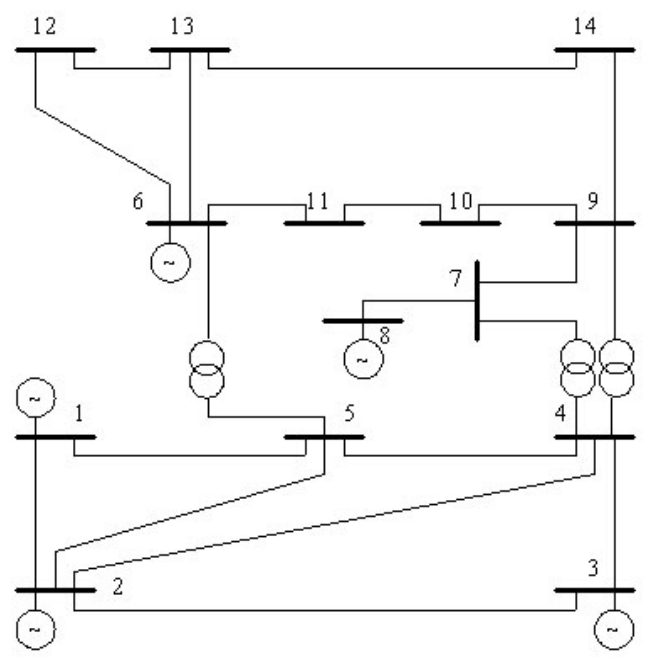

Figure 5: Test case 14-bus system

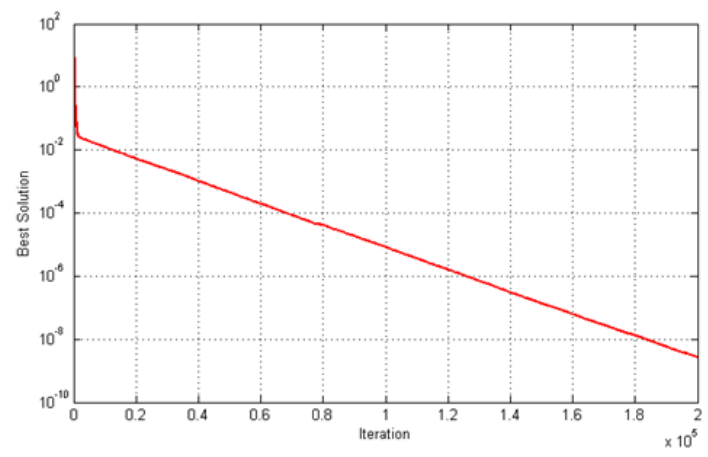

Nrar $=22 ; \mathrm{Lb}, \mathrm{Ub}=0.5 \leq|V| \leq 1.05,-5 \leq \delta \leq 5 ; \mathrm{nPop}=7 ;$ nOnlooker=28; MaxIt=2× $10^{\mathrm{b}} ; \mathrm{L}=13000 ; \mathrm{A}=1$.

Figure 6: The performance of $\mathrm{ABC}$ algorithm, best solution value versus iteration
Table 6: Results of system (bus voltages)

\begin{tabular}{|c|c|c|c|c|}
\hline \multirow{2}{*}{$\begin{array}{c}\text { Bus } \\
\text { No. } \\
\text { (i) }\end{array}$} & \multicolumn{2}{|c|}{ NR-method } & \multicolumn{2}{c|}{ ABC-algorithm } \\
\cline { 2 - 5 } & $V_{i}$ & $\delta_{\mathrm{i}}$ & $V_{i}$ & $\delta_{\mathrm{i}}$ \\
\hline 1 & 1.0500 & 0 & 1.0500 & 0 \\
\hline 2 & 1.0400 & -6.1641 & 1.0400 & -6.1641 \\
\hline 4 & 1.0350 & -13.2308 & 1.0350 & -13.2308 \\
\hline 5 & 0.9956 & -12.1726 & 0.9956 & -12.1726 \\
\hline 5 & 0.9973 & -10.6553 & 0.9973 & -10.6553 \\
\hline 6 & 1.0400 & -19.6049 & 1.0400 & -19.6049 \\
\hline 7 & 1.0148 & -17.6030 & 1.0148 & -17.6030 \\
\hline 8 & 1.0400 & -19.3628 & 1.0400 & -19.3628 \\
\hline 9 & 1.0006 & -19.3632 & 1.0006 & -19.3632 \\
\hline 10 & 0.9973 & -19.9492 & 0.9973 & -19.9492 \\
\hline 11 & 1.0097 & -20.2317 & 1.0097 & -20.2317 \\
\hline 12 & 0.9961 & -20.5128 & 0.9961 & -20.5128 \\
\hline 13 & 1.0097 & -20.5537 & 1.0097 & -20.5537 \\
\hline 14 & 0.9901 & -20.8042 & 0.9901 & -20.8042 \\
\hline
\end{tabular}

Table 7: Results of system by using NR method (power flow in lines)

\begin{tabular}{|c|c|c|c|c|c|}
\hline \multicolumn{2}{|c|}{ The lines } & \multirow{2}{*}{$\begin{array}{c}\mathrm{P}_{\mathrm{ij}} \\
\text { i }\end{array}$} & $\begin{array}{c}\mathrm{Q}_{\mathrm{ij}} \\
(\mathrm{MW})\end{array}$ & $\begin{array}{c}\mathrm{P}_{\mathrm{ji}} \\
(\mathrm{MVAR})\end{array}$ & $\begin{array}{c}\mathrm{Q}_{\mathrm{ji}} \\
(\mathrm{MW})\end{array}$ \\
\hline 1 & 2 & 187.3716 & -32.9546 & -181.009 & 52.3796 \\
\hline 1 & 5 & 89.5267 & 11.2106 & -85.5372 & 5.2584 \\
\hline 2 & 3 & 64.8415 & -8.6338 & -62.9825 & 16.4657 \\
\hline 2 & 4 & 64.1892 & 8.2466 & -61.9391 & -1.4190 \\
\hline 2 & 5 & 50.2786 & 10.8946 & -48.8850 & -6.6399 \\
\hline 3 & 4 & -1.5175 & 24.5268 & 1.8952 & -23.5627 \\
\hline 4 & 5 & -57.6481 & 15.1013 & 58.1263 & -13.5926 \\
\hline 4 & 7 & 46.7537 & -7.1342 & -46.7537 & 11.7492 \\
\hline 4 & 9 & 23.1382 & 0.5306 & -23.1382 & 2.3817 \\
\hline 5 & 6 & 68.6959 & -12.7480 & -68.6959 & 24.2759 \\
\hline 6 & 11 & 10.8779 & 10.6856 & -10.6737 & -10.2580 \\
\hline 6 & 12 & 12.2063 & 12.0504 & -11.8720 & -11.3546 \\
\hline 6 & 13 & 20.4117 & 13.9107 & -20.0385 & -13.1759 \\
\hline 7 & 8 & 18.4000 & -14.2169 & -18.4000 & 15.1417 \\
\hline 7 & 9 & 28.3537 & 13.5461 & -28.3537 & -12.4913 \\
\hline 9 & 10 & 11.9049 & -0.4596 & -11.8599 & 0.5793 \\
\hline 9 & 14 & 9.0869 & -0.2717 & -8.9820 & 0.4949 \\
\hline 10 & 11 & -0.1401 & -6.3793 & 0.1737 & 6.4580 \\
\hline 12 & 13 & -3.2280 & -3.2454 & 3.2746 & 3.2876 \\
\hline 13 & 14 & 3.2639 & 4.0883 & -3.2180 & -3.9949 \\
\hline
\end{tabular}

Table 8: Results of system by using ABC algorithm (power flow in lines)

\begin{tabular}{|c|c|c|c|c|c|}
\hline \multicolumn{2}{|c|}{ The lines } & \multirow{2}{*}{$\begin{array}{c}\mathrm{P}_{\mathrm{ij}} \\
\text { (MW) }\end{array}$} & $\begin{array}{c}\mathrm{Q}_{\mathrm{ij}} \\
(\mathrm{MVAR})\end{array}$ & $\begin{array}{c}\mathrm{P}_{\mathrm{ji}} \\
(\mathrm{MW})\end{array}$ & $\begin{array}{c}\mathrm{Q}_{\mathrm{ji}} \\
(\mathrm{MVAR})\end{array}$ \\
\hline 1 & 2 & 187.3716 & -32.9546 & -181.009 & 52.3796 \\
\hline 1 & 5 & 89.5267 & 11.2106 & -85.5372 & 5.2584 \\
\hline 2 & 3 & 64.8415 & -8.6338 & -62.9825 & 16.4657 \\
\hline 2 & 4 & 64.1892 & 8.2466 & -61.9391 & -1.4190 \\
\hline 2 & 5 & 50.2786 & 10.8946 & -48.8850 & -6.6399 \\
\hline 3 & 4 & -1.5175 & 24.5268 & 1.8952 & -23.5627 \\
\hline 4 & 5 & -57.6481 & 15.1013 & 58.1263 & -13.5926 \\
\hline 4 & 7 & 46.7537 & -7.1342 & -46.7537 & 11.7492 \\
\hline
\end{tabular}




\begin{tabular}{|c|c|c|c|c|c|}
\hline 4 & 9 & 23.1382 & 0.5306 & -23.1382 & 2.3817 \\
\hline 5 & 6 & 68.6959 & -12.7480 & -68.6959 & 24.2759 \\
\hline 6 & 11 & 10.8779 & 10.6856 & -10.6737 & -10.2580 \\
\hline 6 & 12 & 12.2063 & 12.0504 & -11.8720 & -11.3546 \\
\hline 6 & 13 & 20.4117 & 13.9107 & -20.0385 & -13.1759 \\
\hline 7 & 8 & 18.4000 & -14.2169 & -18.4000 & 15.1417 \\
\hline 7 & 9 & 28.3537 & 13.5461 & -28.3537 & -12.4913 \\
\hline 9 & 10 & 11.9049 & -0.4596 & -11.8599 & 0.5793 \\
\hline 9 & 14 & 9.0869 & -0.2717 & -8.9820 & 0.4949 \\
\hline 10 & 11 & -0.1401 & -6.3793 & 0.1737 & 6.4580 \\
\hline 12 & 13 & -3.2280 & -3.2454 & 3.2746 & 3.2876 \\
\hline 13 & 14 & 3.2639 & 4.0883 & -3.2180 & -3.9949 \\
\hline
\end{tabular}

\subsection{Test case 14-bus ill conditioned power system}

When the prescribed range of $(\mathrm{R} / \mathrm{X})$ ratio for a transmission lines in system is increased by 3.14 times, the conventional NR method failed to converge, while the (ABC) algorithm converged to the solutions shown in table (9). After initialize the control parameters of $\mathrm{ABC}$, The final objective function value in $\mathrm{ABC}$ optimization process after 15000 iteration is $4.526 \times 10^{-4}$. The performance of $\mathrm{ABC}$ method to obtain the best solution is clarified by graph that shown in Fig (7).

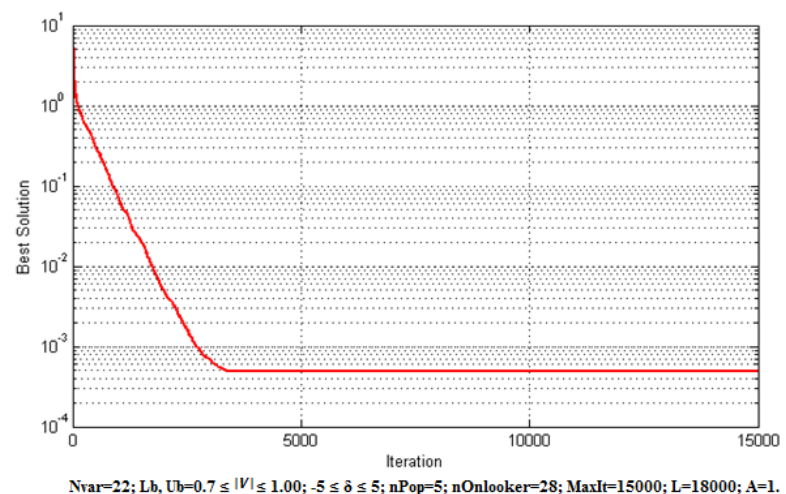

Figure 7: the performance of $\mathrm{ABC}$ algorithm, best solution value versus iteration

Table 9: Results of system by using $\mathrm{ABC}$ algorithm (buses voltages)

\begin{tabular}{|c|c|c|}
\hline \multirow{2}{*}{$\begin{array}{c}\text { Bus No. } \\
\text { (i) }\end{array}$} & \multicolumn{2}{|c|}{ ABC-algorithm } \\
\cline { 2 - 3 } & $V_{i}$ & $\delta_{\mathrm{i}}$ \\
\hline 1 & 1.0500 & 0 \\
\hline 2 & 1.0400 & -36.0020 \\
\hline 4 & 1.0350 & -55.3166 \\
\hline 5 & 0.8863 & -42.2674 \\
\hline 5 & 0.8836 & -36.9360 \\
\hline 6 & 1.0400 & -49.4221 \\
\hline 7 & 0.9527 & -47.8616 \\
\hline 8 & 1.0400 & -49.7349 \\
\hline 9 & 0.9255 & -49.4257 \\
\hline 10 & 0.9165 & -49.5676 \\
\hline 11 & 0.9504 & -49.6177 \\
\hline
\end{tabular}

\begin{tabular}{|l|l|l|}
\hline 12 & 0.9351 & -47.9158 \\
\hline 13 & 0.9588 & -49.3720 \\
\hline 14 & 0.8925 & -49.9392 \\
\hline
\end{tabular}

Table 10: Results of system by using ABC algorithm (power flow in lines)

\begin{tabular}{|c|c|c|c|c|c|}
\hline \multicolumn{2}{|c|}{ The lines } & \multirow{2}{*}{$\begin{array}{c}\mathrm{P}_{\mathrm{ij}} \\
\text { i }\end{array}$} & $\begin{array}{c}\mathrm{Q}_{\mathrm{ij}} \\
(\mathrm{MW})\end{array}$ & $\begin{array}{c}\mathrm{P}_{\mathrm{ji}} \\
(\mathrm{MVAR})\end{array}$ & $\begin{array}{c}\mathrm{Q}_{\mathrm{ji}} \\
(\mathrm{MW})\end{array}$ \\
\hline $\mathrm{M}$ & 2 & 559.0200 & -387.770 & -222.172 & 636.1871 \\
\hline 1 & 5 & 205.5291 & -44.3217 & -115.839 & 133.7534 \\
\hline 2 & 3 & 108.1024 & -72.9999 & -77.4987 & 104.1435 \\
\hline 2 & 4 & 64.6382 & 5.5576 & -55.2763 & 1.3037 \\
\hline 2 & 5 & 47.7405 & 28.8544 & -40.9574 & -23.8519 \\
\hline 3 & 4 & 13.0197 & 82.6894 & 5.1269 & -71.5021 \\
\hline 4 & 5 & -56.8516 & 88.3550 & 64.6175 & -82.4381 \\
\hline 4 & 7 & 40.2479 & -26.7765 & -40.2479 & 32.8601 \\
\hline 4 & 9 & 18.9670 & -5.2517 & -18.9670 & 7.9088 \\
\hline 5 & 6 & 84.5903 & -49.5681 & -84.5903 & 78.4837 \\
\hline 6 & 11 & 19.2082 & 8.8579 & -17.5816 & -8.0352 \\
\hline 6 & 12 & 15.1571 & 12.6436 & -13.3242 & -11.7222 \\
\hline 6 & 13 & 25.0368 & 12.2278 & -23.0710 & -11.2927 \\
\hline 7 & 8 & 18.3860 & -46.9292 & -18.3860 & 51.8598 \\
\hline 7 & 9 & 21.8758 & 23.8328 & -21.8758 & -22.5643 \\
\hline 9 & 10 & 5.1935 & 1.7374 & -5.1474 & -1.7078 \\
\hline 9 & 14 & 5.1632 & 1.2461 & -4.9899 & -1.1571 \\
\hline 10 & 11 & -6.8384 & -4.0909 & 7.0951 & 4.2360 \\
\hline 12 & 13 & -1.7619 & -2.8761 & 1.8809 & 2.9021 \\
\hline 13 & 14 & 7.7035 & 2.5915 & -7.1950 & -2.3414 \\
\hline
\end{tabular}

\section{CONCLOUSION}

This paper presents an efficient load flow computation by using $\mathrm{ABC}$ algorithm that is considered to be one type of swarm intelligence techniques. This algorithm is applied to 6 and 14 bus systems with different conditions, the results obtained have been compared with the results of NR method. The main advantages of $\mathrm{ABC}$ algorithm are the flexibility of modeling, accuracy, strong convergence and reliability. In addition, the presented algorithm shows promising results regarding heavily loaded and ill-conditioned systems. For the future work, the control parameters of the $\mathrm{ABC}$ algorithm in this field require comprehensive study to choose the best initial setting of the parameters' values to make this algorithm more powerful and able to be applied on large and practical models of power systems. In addition, the proposed algorithm could be used in many studies in power system such as optimal power flow, state estimation and stability studies.

\section{ACKNOWLEDGMENTS}

The authors would like to thank Al-Mustansiriyah University (www.uomustansiriyah.edu.iq)Baghdad-Iraq for its support in the present work

\section{REFERENCES}

[1] Stott, B. "Review of load-flow calculation methods", Proc. IEEE, Vol.62, pp.916-929, Jul. 1974.

[2] Wu, F.F. "Theoretical Study of the Convergence of the Fast Decoupled Load Flow", IEEE Trans. Power Syst., Vol.96, pp.269-275, Jan/Feb. 1977.

[3] Guo, S.X. and A.Salam, F.M. "Determining The Solutions of The Load Flow Of Power System", Theoretical of 
results and computer implementation proceeding of the $29^{\text {th }}$ conference on precision and control, USA PP.15611566, Hawaii, December, 1990.

[4] Cutsem, T.V. and Vournas, C. "Voltage stability of Electric Power System", Kluwer Academic Publishers, USA, 1998

[5] Seydel and Rüdiger "Practical Bifurcation and Stability from Equilibrium to Chaos", $2^{\text {nd }}$ Edition, SoringerVerlag, 1994

[6] Wang, Y., da Silva, L. C. P. and Xu, W. "Investigation of The Relationship between Ill-conditioned Power Flow and Voltage Collapse",IEEE Trans. Power Syst., Vol.20, pp. 43-45., 2000.

[7] Ajjarapu, V. and Christy, C. "The Continuation Power Flow: A Tool For Steady-State Voltage Stability Analysis ", Transactions on Power Systems, Vol.7, No.1, PP.416-423, Feb.1992.

[8] Alves, D. A. , da Silva, L. C. P. , Castro, C. A. and da Costa V. F. ," Continuation Fast Decoupled Power Flow With Secant Predictor", IEEE Transaction on Power Systems, Vol.18,No.3, pp 1078-1085, Aug.2003.

[9] Karaboga, D. "An Idea Based On Honey Bee Swarm for Numerical Optimization" Technical Report-TR06, Kayseri, Turkey: Erciyes University; 2005.

[10] Akay, B. and Karaboga, D. "A Modified Artificial Bee Colony Algorithm For Real-Parameter Optimization" Information science Vol.1, pp. 120-142,June 2010.

[11] Huang, S. J. , Liu, X.Z. , Su, W.F. and Ou, T.C. " Application of Enhanced Honey - Bee Mating Optimization Algorithm to Fault Section Estimation in Power Systems ",IEEE Transaction on Power Delivery,vol.28,Issue 3, PP.1944-1951, July 2013.

[12] Safari, A., Ahmadian, A. and Golker, M.A.A. "Controller Design Of STATCOM For Power System Stability Improvement Using Honey Bee Mating Optimization", Journal of Applied Research and Technology Vol.11, Issue 1, PP.144-155, Feb. 2012.

[13] Afzalan, M. and Taghikhani, M. A."Placement and Sizing DG Using PSO \& HBMO Algorithms in Radial Distribution Networks" International Journal of Intelligent System and Applications, Vol.4, No.10 ,PP. 43-49, September 2012.

[14] Linh, N.T. and Dong, D. X. "Optimal Location and Size of Distributer Generation in Distribution System by Artificial Bees Colony Algorithm”, International journal of Information and Electronics Engineering, Vol.3, No.1, PP.63-67, Jan .2013.

[15] Graniger, J.J. and Stevenson, W.D. Jr.: "Power System Analysis" (McGraw-Hill, 1994).

[16] Kiran, M. S. and Gündüz, M. "The Analysis of Peculiar Control Parameters of Artificial Bee Colony Algorithm on the Numerical Optimization Problems", Journal of Computer and Communications, Vol.2, PP: 127-136, March 2014
[17] Al-Anbarri, K. A., Miri, A. H. and Hussain, S. A. "Load Frequency Control of Multi - area Hybrid Power System by Artificial Intelligence Techniques", International Journal of Computer Applications (0975 - 8887, Volume 138 - No.7, March 2016.

[18] Minhat, A. R., Mustafa, M. W. and Musirin, I. "Transmission Line Loss and Load Allocation via Artificial Bee Colony Algorithm", IEEE International Conference on power and Energy (PECon), Kota kinablalu sabah , Malaysia, 2-5 December 2012.

[19] Wood, A. J. and Wollenberg, B. F. "Power Generation, Operation And Control", John Wiley \& Sons Ltd., 2nd Edition, 1996.

[20] Srikanth, P., Rajendra, O., Yesuraj, A., Tilak, M. and Raja, K. "Load Flow Analysis of IEEE14 Bus System Using MATLAB", International Journal of Engineering Research \& Technology (IJERT) Vol. 2 Issue 5, pp. 2278-0181, May 2013

\section{APPENDIX A}

Buses Data of 6-bus case with heavily loaded condition

\begin{tabular}{|c|c|c|c|c|c|c|c|}
\hline $\begin{array}{c}\text { Bus } \\
\text { No. }\end{array}$ & $\begin{array}{c}\text { Bus } \\
\text { code }\end{array}$ & $\begin{array}{c}V_{\text {mag }} \\
\text { Volt }\end{array}$ & $\begin{array}{c}\delta \\
\text { Deg }\end{array}$ & $\begin{array}{c}P_{\text {gen }} \\
\text { MW }\end{array}$ & $\begin{array}{c}Q_{\text {gen }} \\
\text { MVAR }\end{array}$ & $\begin{array}{c}P_{\text {load }} \\
\text { MW }\end{array}$ & $\begin{array}{c}Q_{\text {load }} \\
\text { MVAR }\end{array}$ \\
\hline 1 & 1 & 1.05 & 0 & 0 & 0 & 0 & 0 \\
\hline 2 & 2 & 1.05 & 0 & 80 & 0 & 0 & 0 \\
\hline 3 & 2 & 1.07 & 0 & 90 & 0 & 0 & 0 \\
\hline 4 & 3 & 1.0 & 0 & 0 & 0 & 255 & 130 \\
\hline 5 & 3 & 1.0 & 0 & 0 & 0 & 255 & 130 \\
\hline 6 & 3 & 1.0 & 0 & 0 & 0 & 254.13 & 152 \\
\hline
\end{tabular}

\section{APPENDIX B}

Buses Data of 14-bus case with and without high R/X ratio

\begin{tabular}{|c|c|c|c|c|c|c|c|}
\hline $\begin{array}{c}\text { Bus } \\
\text { No. }\end{array}$ & $\begin{array}{c}\text { Bus } \\
\text { code }\end{array}$ & $\begin{array}{c}V_{\text {mag }} \\
\text { volt }\end{array}$ & $\begin{array}{c}\delta \\
\text { Deg }\end{array}$ & $\begin{array}{c}P_{\text {gen }} \\
\text { MW }\end{array}$ & $\begin{array}{c}Q_{\text {gen }} \\
\text { MVAR }\end{array}$ & $\begin{array}{c}P_{\text {load }} \\
\text { MW }\end{array}$ & $\begin{array}{c}Q_{\text {load }} \\
\text { MVAR }\end{array}$ \\
\hline 1 & 1 & 1.05 & 0 & 0 & 0 & 0 & 0 \\
\hline 2 & 2 & 1.04 & 0 & 60 & 32.4 & 61.7 & 42.7 \\
\hline 3 & 2 & 1.035 & 0 & 0 & 23.4 & 64.5 & 29 \\
\hline 4 & 3 & 1.0 & 0 & 0 & 0 & 47.8 & 3.9 \\
\hline 5 & 3 & 1.0 & 0 & 0 & 0 & 7.6 & 1.6 \\
\hline 6 & 2 & 1.04 & 0 & 0 & 12.2 & 25.2 & 18.5 \\
\hline 7 & 3 & 1.0 & 0 & 0 & 0 & 0 & 0 \\
\hline 8 & 2 & 1.04 & 0 & 0 & 17.4 & 18.4 & 12.8 \\
\hline 9 & 3 & 1.0 & 0 & 0 & 0 & 30.5 & 16.6 \\
\hline 10 & 3 & 1.0 & 0 & 0 & 0 & 12 & 5.8 \\
\hline 11 & 3 & 1.0 & 0 & 0 & 0 & 10.5 & 3.8 \\
\hline 12 & 3 & 1.0 & 0 & 0 & 0 & 15.1 & 14.6 \\
\hline 13 & 3 & 1.0 & 0 & 0 & 0 & 13.5 & 5.8 \\
\hline 14 & 3 & 1.0 & 0 & 0 & 0 & 12.2 & 3.5 \\
\hline
\end{tabular}

- Bus code: 1=slack bus , 2=voltage controlled bus(PV bus) \& 3=load bus (PQ bus) 